\title{
Dietary patterns among adolescents in the West of Scotland
}

\author{
BY ANNIES. ANDERSON, SALLY MACINTYRE* AND PATRICK WEST \\ MRC Medical Sociology Unit, 6 Lilybank Gardens, Glasgow G12 $8 Q Q$
}

(Received 11 June 1992 - Revised 4 January 1993 - Accepted 17 February 1993)

\begin{abstract}
Dietary data from 15-year-old adolescents participating in the West of Scotland Twenty-07 study were examined in order to describe current eating patterns and food habits. Comparison of the data with a 'healthy eating' index showed that less than one-third of the sample were eating a diet similar to that promoted by local health education campaigns. Multivariate analysis showed that adolescents from nonmanual and wealthier families, non-smokers, and females were more likely to be classified as 'healthy eaters'. Comparison of the data with that collected from a 35-year-old cohort in the same study showed that significantly fewer 15-year-olds were likely to consume diets associated with long-term health.
\end{abstract}

Adolescence: Diet: Scotland

The diet of British school-children has received much publicity in recent years (Department of Health 1989; Nelson et al. 1990; MacNeill et al. 1991) following a number of surveys which indicate that some school children are consuming diets low in energy (Department of Health, 1989), Fe, thiamine, and riboflavin (Bull, 1985) and vitamins in general (MacNeill et al. 1991). Many children have diets high in fat (Wenlock, 1990) and sugar (Hackett et al. 1986). These findings are of concern because such diets may affect day-to-day well-being, growth, dental health, physical development and academic achievement. In addition, dietary habits developed during adolescence may form the basis for adult eating habits. As matters stand, the diets of British children appear to be generating future risks of chronic diseases and certain cancers (World Health Organization, 1990).

Three key influences on food intake in adolescents (as opposed to younger age-groups) have been described by Truswell \& Darton-Hill (1981): altered meal patterns (e.g. snacking), changing food consumption (e.g. alcohol/coffee), and concern with body weight (e.g. appearance). It has been suggested (Thomas, 1990) that many of these features reflect teenagers' needs to express their freedom from parental control and from adult tastes and lifestyles. Thus, nutrition education has to operate against a background of young people's desires for autonomy over food choices, and of a flourishing 'youth industry' aimed at encouraging adolescents to purchase non-traditional fast foods. Additionally, much of nutrition education is based on the relationship between nutrition and the prevention of conditions such as coronary heart disease which develop in middle age and which may therefore be seen, by teenagers, as being of little relevance to themselves.

The present paper describes eating patterns among 15-year-olds living in the late 1980s in the Central Clydeside Conurbation, an area in the West of Scotland with high rates of premature mortality from coronary heart disease and a reputation for unhealthy dietary patterns (Smith et al. 1989; Turnstall-Pedoe et al. 1989). In an earlier paper (Anderson \& Hunt, 1992) we described diets among a sample of 35-year-olds in the same area. Males, people from lower income or manual social class households, and smokers were more likely than others to report diets classified as 'less healthy' according to current nutritional theories, and in particular according to the dietary guidelines promulgated locally as part 
of the 'Goodhearted Glasgow' health promotion campaign (Greater Glasgow Health Board, 1987). In the present paper we use a similar measure of 'healthy' and 'less healthy' diets to examine socio-demographic predictors of reported diets among a younger agegroup.

\section{SUBJECTS AND METHODS}

The data were collected as part of The West of Scotland Twenty-07 Study: Health in the Community (Macintyre et al. 1989) which aims to examine the relationship between health and six social factors (social class, age, sex, marital status, ethnicity and area of residence). The design involves longitudinal surveys of three age-cohorts, aged 15, 35 and 55 years at the baseline surveys in 1987-8. Data on the 15-year-olds presented in the present paper were gathered in 1987 .

For each cohort the sample is based on a two-stage stratified random clustered design, using fifty-two post code sectors as primary sampling units, covering the Central Clydeside Conurbation (CCC; Ecob, 1987). In 1981 the CCC, which consists of Glasgow City and ten adjacent local government districts, all within Strathclyde Region, had a population of 1.7 million, and an all-cause standardized mortality ratio (SMR) of 109 compared with 100 for Scotland as a whole (MacIver, 1988).

The sampling frame was an enhanced electoral register (the Voluntary Population Survey) which listed the age and sex composition of all households in Strathclyde Region (Black, 1985). Regional Council Staff drew a random sample of 1682 households recorded in 1986 as containing someone born between 1.3 .71 and 29.2.72, and approached them for permission to pass their names to MRC researchers. Of the target individuals and/or their parents, $15 \%$ refused consent, $10 \%$ could not be contacted after four attempts, and $5 \%$ had moved between the sample being drawn and the attempted contact. Of the 1177 who agreed to be contacted, 1009 were interviewed, representing $60 \%$ of the initial target sample (65\% if those known to have moved are excluded).

Each participant underwent two face-to-face interviews and also completed a selfadministered questionnaire. The first interview collected a range of data on personal and social circumstances, health knowledge, health beliefs and values, and health-related behaviours (including diet, alcohol consumption, exercise and smoking). The second interview was conducted by trained nurses and focused on self-assessed and self-reported health and measures of physical functioning and development (including height and weight). A face-to-face interview was also conducted with one or both parents of each young person. The self-administered questionnaire (which was completed between the first and the second interview) included a dietary inventory and some mental health and attitudinal scales. The dietary inventory was intended to establish food consumption habits and was based, in format and content, on that used in the Health and Lifestyle Survey (Cox et al. 1987). Respondents were asked how often they consumed twenty-eight food and drink items, using the following frequency categories; 'more than once daily', 'once daily', 'most days', 'once or twice weekly', 'less than once weekly', or 'never'. No attempt was made to identify portion weight, and quantitative estimates of nutrient intakes could not be calculated from the information collected. Data from this self-completion food-frequency inventory were available for 917 subjects ( $55 \%$ of the initial target sample); there were further missing data on some individual items. In addition, in the main interview schedule, completed by 1009 subjects, there were ten questions on diet, ranging from meal patterns to food preferences, plus a question about knowledge of foods which are good for slimming diets.

To assess these reported eating patterns a 'healthy eating' index was calculated, based on a quiz developed by Greater Glasgow Health Board (1987) as part of their health 
promotion literature directed at the general public. This quiz was designed as a selfassessment test and comprised twelve questions, six of which covered the quantity and quality of fat consumed, (scored to produce a total 'fat score', range 1-24), and six of which covered quantity and quality of food high in fibre-rich carbohydrate (scored to produce a 'carbohydrate' score, range 1-18). Persons eating the highest amount of fat scored the highest fat score and those eating the highest amount of fibre-rich carbohydrate scored the highest carbohydrate score. Individuals were defined as 'healthy eaters' if their fat score was less than their carbohydrate score, and as 'less healthy eaters' if their fat scores were equal to or greater than their carbohydrate scores.

Data on eight of the items covered in this quiz were collected on teenagers in the Twenty07 Study. For the fat score these were: What type of milk do you usually use? How often do you eat cheese? How often do you eat chips? How often do you eat sausages, meat pies or burgers? For the carbohydrate score they were: What kind of bread do you usually eat? How many times weekly do you eat a breakfast cereal? How often do you eat fresh fruit? (the mean being taken of the responses to two fruit-frequency questions, fruit consumption in summer and winter), and How often do you eat fresh vegetables? (a mean being taken of reported summer and winter consumption of salads, root vegetables, peas and cooked green vegetables). The answers were scored as in the Greater Glasgow Health Board (1987) quiz, summed, and those with higher carbohydrate than fat scores were defined as 'healthy eaters', and those with fat scores higher than, or the same as, carbohydrate scores were defined as 'less healthy eaters'. Data necessary for the computation of this 'healthy eating' variable were available for 843 subjects, $50 \%$ of the initial target sample.

The variables used to examine the social patterning of the 'healthy diet' index were sex, Registrar General's classification of the occupation of the head of household (Office of Population Censuses and Surveys, 1981), household income as reported by a parent, and smoking. These were chosen because they have been shown to be predictors of dietary patterns among adults (Cox et al. 1987; Smith et al. 1989; Blaxter, 1991; Anderson \& Hunt, 1992), and we wished to ascertain whether they had similar predictive value for 15 year olds. In addition, we wished to look at whether the few who had left school by the time they were interviewed differed from those still at school. All these socio-demographic variables were coded as dichotomies, i.e. male $(47.8 \%) v$. female $(52.2 \%)$; non-manual $(41.3 \%) v$. manual $(58.7 \%)$; current smokers (those reporting themselves as being regular or occasional smokers, $17.5 \%) v$. non-smokers $(82.5 \%)$; those still at school $(91.9 \%) v$. those who had officially left $(8.1 \%)$. Information on total net household income was elicited in pre-coded bands to enhance response to this sensitive question. The best break in the data was approximate thirds; here we use the lowest third (less than $£ 130$ per week, $39.5 \%$ households) compared with the middle third ( $£ 130-£ 199$ per week $(30.5 \%))$ and highest third ( $£ 200$ or more per week $(29.9 \%)$ ) combined.

\section{Statistical methods}

All data were analysed using SPSS-X (SPSS-X Inc., 1990). For the food-frequency distribution the denominator is the total sample. For the assessment of 'healthy eating', data were only used from respondents who had completed all the food-frequency items used in the calculation of the 'healthy eating' index.

Initially, univariate relationships between 'healthy eating' status and the sociodemographic variables were examined and the difference in distributions assessed by using the chi-square test. Logistic regression was used to examine the relative importance of the explanatory variables, adjusting for the other independent variables. 


\section{RESULTS \\ Measured and self-perceived body size}

The mean height of the males was 1.72 (SD 0.07) $\mathrm{m}$ and of females $1.62(\mathrm{SD} 0.06) \mathrm{m}$. The mean weight for males was 59.9 (SD 10.2) kg, and for females it was 55.2 (SD 8.7) kg. Body mass index (BMI), here defined by (measured) weight $(\mathrm{kg}) /$ height $\left(\mathrm{m}^{2}\right)$, was 20.3 (SD 2.8) for males and $21 \cdot 1$ (SD 3.1) for females. Of the males, $19 \%$ thought they were too light for their height, $16.1 \%$ too heavy, and $63.8 \%$ 'about right'. Among the females the corresponding proportions were very different; $7 \cdot 4 \%$ thought they were too light, $49 \cdot 1 \%$ too heavy and only $43.3 \%$ 'about right'.

\section{Dietary knowledge}

The findings showed that $49 \%$ reported receiving health education lessons in school on diet (compared with $75.4 \%$ reporting lessons on personal hygiene, $73.5 \%$ on drugs, $72.2 \%$ on exercise and $70.2 \%$ on smoking). A crude measure of their knowledge of healthy but nonfattening foods was obtained by asking the question: "If someone asked you whether the following foods were good or bad for them if they wanted to lose weight or remain slim while remaining healthy, what would you say?'. A total of $99.5 \%$ described fresh fruit, $99.3 \%$ fresh vegetables, and $93.4 \%$ fish as good in this context, while only $5.7 \%$ described pastries/pies, $0.7 \%$ chips and $0.4 \%$ sweets/lollies as good for the healthy weight-watcher. This suggests that, at the extremes at least, they were not ignorant about what the current orthodoxy regards as a healthy diet. They were less certain about other foods, however, only $79.6 \%, 76.0 \%$ and $58.8 \%$ respectively describing jacket potatoes, bread and red meat as healthy but non-fattening.

\section{Food habits and preferences}

Respondents were asked what sorts of milk, spreads, and bread they normally ate, and what they preferred. The survey showed that $65 \%$ reported drinking 'ordinary' milk, $30 \%$ semi-skimmed milk, and $4 \%$ reported not drinking milk. There were $34 \%$ who reported eating butter, $53 \%$ soft margarines and $1.5 \%$ hard margarines (the remainder reported not using spreads or not eating bread). Of the respondents, $80 \%$ reported eating white bread, $19 \%$ brown or wholemeal bread, and $1 \%$ eating other breads or not eating bread. Thus, over half were eating the 'healthier' alternative forms of spread, compared with just under one-third drinking a 'healthier' form of milk and only one-fifth eating the 'healthier' form of bread.

With regard to preferences, an identical proportion preferred semi-skimmed milk as reported actually drinking it $(30 \%)$. Slightly fewer preferred soft margarine than reported eating it (48.2\% compared with $53 \% ; \chi^{2} 4 \cdot 46$, df 1 , not significant), but significantly more said they would prefer to eat brown or wholemeal bread than were actually eating it $(27 \%$ compared with $19 \% ; \chi^{2} 17.96$, df $\left.1, P<0.001\right)$. For all three of these food types, therefore, under half this sample preferred the 'healthier' alternatives.

Milk and sugar consumption associated with beverages was high. Of the $80 \%$ who reported ever drinking tea, $91.8 \%$ reported adding milk, $61.7 \%$ reported adding sugar and $4.6 \%$ sweeteners. Of the $52 \%$ who reported ever drinking coffee, $94.3 \%$ reported adding milk, $70.9 \%$ sugar and $7 \cdot 1 \%$ sweeteners. Of the 917 who completed the dietary inventory, $58 \%$ reported drinking bottled or canned soft drinks at least once daily, and $34.2 \%$ reported drinking 'Irn Bru' (a popular Scottish type of fizzy drink) at least daily (see Table 1).

\section{Food frequencies}

The frequency of reported consumption of the twenty-eight items in the dietary inventory is presented in Table 1, divided into food types. The items most likely to be reported as 
Table 1. Frequency (\%) of reported consumption of common dietary items by 1009 West of Scotland 15-year-olds

\begin{tabular}{|c|c|c|c|c|c|}
\hline & $\begin{array}{l}\text { At least } \\
\text { once daily }\end{array}$ & $\begin{array}{l}\text { Three to six } \\
\text { times } \\
\text { weekly }\end{array}$ & $\begin{array}{c}\text { Once or twice } \\
\text { weekly }\end{array}$ & $\begin{array}{c}\text { Less than } \\
\text { weekly/ } \\
\text { never }\end{array}$ & $\begin{array}{c}\text { Missing } \\
\text { information }\end{array}$ \\
\hline \multicolumn{6}{|l|}{ Snack foods } \\
\hline Crisps & 43 & 27 & 14 & 6 & 10 \\
\hline Sweets/chocolate & 42 & 26 & 16 & 6 & 10 \\
\hline Cakes & 11 & 16 & 36 & 27 & 10 \\
\hline Biscuits & 43 & 26 & 15 & 6 & 10 \\
\hline Fresh fruit(S) & 43 & 24 & 18 & 6 & 9 \\
\hline Fresh fruit(W) & 20 & 20 & 32 & 19 & 9 \\
\hline \multicolumn{6}{|l|}{ Main meal items } \\
\hline \multicolumn{6}{|l|}{ Meat/fish } \\
\hline Beef/lamb/pork & 9 & 22 & 44 & 15 & 10 \\
\hline Poultry & 2 & 8 & 42 & 37 & 11 \\
\hline Fish & 1 & 4 & 34 & 50 & 11 \\
\hline Cheese & 16 & 27 & 30 & 17 & 10 \\
\hline Eggs & 10 & 23 & 35 & 22 & 10 \\
\hline Sausage/tinned meat & 7 & 14 & 42 & 27 & 10 \\
\hline Meat pies/pasties & 4 & 10 & 34 & 42 & 10 \\
\hline \multicolumn{6}{|l|}{ Potatoes etc. } \\
\hline Pasta/rice & 3 & 8 & 40 & 40 & 9 \\
\hline Potatoes & 11 & 36 & 34 & 9 & 10 \\
\hline Chips & 15 & 32 & 31 & 13 & 9 \\
\hline \multicolumn{6}{|l|}{ Vegetables } \\
\hline Salads(S) & 19 & 27 & 28 & 16 & 10 \\
\hline Salads(W) & 4 & 7 & 23 & 56 & 10 \\
\hline Root vegetables & 5 & 16 & 32 & 37 & 10 \\
\hline Cooked green vegetables & 8 & 16 & 28 & 37 & 11 \\
\hline Peas and beans & 13 & 33 & 31 & 13 & 10 \\
\hline \multicolumn{6}{|l|}{ Drinks } \\
\hline Fruit juice & 18 & 15 & 21 & 36 & 10 \\
\hline Soft drinks & 52 & 21 & 12 & 5 & 10 \\
\hline Irn Bru & 31 & 17 & 17 & 25 & 10 \\
\hline \multicolumn{6}{|l|}{ Miscellaneous } \\
\hline Cream & 2 & 5 & 16 & 67 & 10 \\
\hline Yoghurt & 8 & 11 & 23 & 47 & 10 \\
\hline Cereals & 50 & 13 & 11 & 16 & 10 \\
\hline Puddings & 12 & 18 & 32 & 28 & 10 \\
\hline
\end{tabular}

S, Summer; $\mathrm{W}$, winter.

being consumed at least daily were crisps, sweets/chocolate, biscuits, fresh fruit in summer, soft drinks and cereals. The majority of the sample ate one or more of these snack foods at least once daily. Poultry, fish, meat pies/pasties, pasta/rice, salads in winter, root vegetables, cooked green vegetables, fruit juice, cream and yoghurt were eaten never, or less than once per week, by over one-third.

\section{'Healthy eating' index}

Only $29.4 \%$ of this sample were classified as 'healthy eaters' using the index derived from the Greater Glasgow Health Board (1987) quiz. Table 2 shows that males, smokers and those from manual or lower income families are more likely to be classified as 'less healthy eaters'. The numbers available for analysis of the possible effects on diet of leaving school are low, and the differences between those in and out of school are not statistically significant. 
Table 2. Distribution of 'healthy eating' according to sex, social class, family income, school status and smoking for 1009 West of Scotland 15-year-olds

\begin{tabular}{|c|c|c|c|c|c|c|c|}
\hline & \multicolumn{2}{|c|}{ 'Healthy eater' } & \multicolumn{2}{|c|}{ 'Less healthy eater' } & \multicolumn{3}{|c|}{ Statistical analysis } \\
\hline & $n$ & $\%$ & $n$ & $\%$ & $x^{2}$ & $\mathrm{df}$ & $P<$ \\
\hline \multicolumn{8}{|l|}{ Sex } \\
\hline Male & 96 & $24 \cdot 1$ & 302 & $75.9\}$ & \multirow{2}{*}{9.7} & \multirow{2}{*}{1} & \multirow{2}{*}{0.005} \\
\hline Female & 152 & $34 \cdot 2$ & 293 & $65.8\}$ & & & \\
\hline \multicolumn{8}{|l|}{ Social class: } \\
\hline Non-manual & 146 & $44 \cdot 4$ & 183 & $55 \cdot 6\}$ & \multirow{2}{*}{$59 \cdot 7$} & \multirow{2}{*}{1} & \multirow{2}{*}{0.001} \\
\hline Manual & 86 & $18 \cdot 7$ & 374 & $81 \cdot 3\}$ & & & \\
\hline \multicolumn{8}{|l|}{ Family income: } \\
\hline$<£ 130$ per week & 149 & $38 \cdot 3$ & 240 & $61 \cdot 7)$ & \multirow[b]{2}{*}{$35 \cdot 3$} & \multirow[b]{2}{*}{1} & \multirow{2}{*}{0.001} \\
\hline$\geqslant £ 130$ per week & 77 & $19 \cdot 0$ & 328 & $81 \cdot 0\}$ & & & \\
\hline \multicolumn{8}{|l|}{ School status: } \\
\hline At school & 235 & $29 \cdot 9$ & 552 & $70 \cdot 1\}$ & \multirow{2}{*}{$0 \cdot 8$} & \multirow[b]{2}{*}{1} & \multirow[b]{2}{*}{ NS } \\
\hline Left school & 13 & $23 \cdot 2$ & 43 & $76.8\}$ & & & \\
\hline \multicolumn{8}{|l|}{ Smoking status: } \\
\hline Non-smoker & 222 & $31 \cdot 5$ & 483 & $68 \cdot 5\}$ & \multirow{2}{*}{$8 \cdot 3$} & \multirow{2}{*}{1} & \multirow{2}{*}{0.005} \\
\hline Smoker & 26 & $18 \cdot 8$ & 112 & $81 \cdot 2\}$ & & & \\
\hline
\end{tabular}

NS, not significant.

To assess the relative importance of the social variables and smoking on 'healthy eating', logistic regression (using loglinear analysis in SPSS) was used to calculate odds ratios. Results of this analysis are given in Table 3. School status is not included in this model because it was significantly related to 'healthy eating' neither on univariate nor multivariate analysis, and because including it does not enhance the fit of the model, which is very good $(P=0.873)$. Even after adjusting simultaneously for the other independent variables, females, those from non-manual or better-off families, and non-smokers were significantly more likely to be 'healthy eaters'. It is interesting that a strong social class effect remained even when income was taken into account.

\section{Comparison with 35-year-olds}

Compared with the 35-year-olds described in our earlier paper (Anderson \& Hunt, 1992), significantly fewer 15-year-olds reported eating brown or wholemeal bread and reduced-fat milk, but similar proportions reported consuming soft margarine (Table 4).

The most noticeable difference between the two age-groups in terms of food frequency was the higher daily consumption among the younger cohort of crisps, sweets and chocolates, biscuits, chips, soft drinks, peas and beans, manufactured meat products, and Irn Bru and other soft drinks (see Table 5). For none of the other items were differences between the cohorts statistically significant.

The 'healthy eating' index was calculated in a slightly different way for the 15-year-olds and 35-year-olds (the interview with the 35-year-olds asked an additional question on the thickness of spreads on bread) so the results in the two cohorts are not strictly comparable; however, far fewer of the younger age-group were classified as 'healthy eaters' $(29 \%$ compared with $42 \% ; \chi^{2} 28 \cdot 15$, df $1, P<0.001$ ). While statistically significant associations with socio-demographic characteristics were found in both samples, the odds ratios produced by the logistic regressions were significantly higher in the older age-group than the younger age-group for sex and class: 2.66 among 35-year-olds compared with 1.31 among 15-year-olds for females compared with males, and 1.87 and 1.77 for non-manual 
Table 3. Odds ratios for 'healthy eating' among 1009 West of Scotland 15-year-olds by sex, social class, family income, and smoking

\begin{tabular}{|c|c|c|c|c|}
\hline & Odds ratio & $95 \%$ C.I. & $\mathrm{Z}$ value & $\begin{array}{c}\text { Statistical } \\
\text { significance } P<\end{array}$ \\
\hline $\begin{array}{l}\text { Males } \\
\text { Females }\end{array}$ & $\left.\begin{array}{l}1 \cdot 00 \\
1.31\end{array}\right\}$ & $1 \cdot 11-1 \cdot 55$ & $3 \cdot 23$ & 0.01 \\
\hline $\begin{array}{l}\text { Manual class } \\
\text { Non-manual class }\end{array}$ & $\left.\begin{array}{l}1.00 \\
1.77\end{array}\right\}$ & $1 \cdot 51-2 \cdot 10$ & $6 \cdot 77$ & 0.001 \\
\hline $\begin{array}{l}<£ 130 \text { per week } \\
\geqslant £ 130 \text { per week }\end{array}$ & $\left.\begin{array}{l}1.00 \\
1.37\end{array}\right\}$ & $1.14-1.65$ & $3 \cdot 38$ & 0.01 \\
\hline $\begin{array}{l}\text { Smoker } \\
\text { Non-smoker }\end{array}$ & $\left.\begin{array}{l}1 \cdot 00 \\
1 \cdot 32\end{array}\right\}$ & $1.03-1.71$ & $2 \cdot 20$ & 0.05 \\
\hline
\end{tabular}

Goodness of fit; likelihood ratio $\chi^{2} 6.00, \mathrm{df} 11, P=0.873$.

Table 4. Comparison between the proportions* of West of Scotland 15-year-olds and 35-year-olds reporting consuming 'healthier' alternatives

\begin{tabular}{|c|c|c|c|c|c|c|c|}
\hline \multirow[b]{2}{*}{ Food type } & \multicolumn{2}{|c|}{ 15-year-olds } & \multicolumn{2}{|c|}{ 35-year-olds } & \multicolumn{3}{|c|}{ Statistical analysis } \\
\hline & $\%$ & $n$ & $\%$ & $n$ & $x^{2}$ & $\mathrm{df}$ & $P<$ \\
\hline Brown/wholemeal bread & $19 \cdot 2$ & 194 & $42 \cdot 2$ & 409 & $120 \cdot 03$ & 1 & $0 \cdot 001$ \\
\hline Semi-skimmed milk & $31 \cdot 6$ & 306 & $41 \cdot 0$ & 371 & $17 \cdot 46$ & 1 & 0.001 \\
\hline Soft margarine & $57 \cdot 7$ & 533 & $54 \cdot 6$ & 512 & $1 \cdot 76$ & 1 & NS \\
\hline
\end{tabular}

NS, not significant.

* The denominators are the numbers in each age-group reporting consuming bread, milk or spreads respectively.

Table 5. Differences between West of Scotland 15-year-olds and 35-year-olds; the reported consumption of certain food items at least once daily (percentage of each agegroup)

\begin{tabular}{lcc}
\hline \hline & $\begin{array}{c}\text { 15-year-olds }(n \text { 1009) } \\
(\%)\end{array}$ & $\begin{array}{c}\text { 35-years-olds }(n 985) \\
(\%)\end{array}$ \\
Crisps & 43 & $6^{* * *}$ \\
Sweets and chocolates & 42 & $8^{* * *}$ \\
Biscuits & 43 & $21^{* * *}$ \\
Chips & 15 & $2^{* * *}$ \\
Potatoes (other than chips) & 11 & $5^{* * *}$ \\
Peas and beans & 13 & $2^{* * *}$ \\
Manufactured meat products & 11 & $8^{* * *}$ \\
Irn Bru & 31 & $15^{* * *}$ \\
Soft drinks & 52 & \\
\hline \hline
\end{tabular}

Values were significantly different from those for 15 -year-olds: ${ }^{* * *} P<0.001$.

compared with manual families. They were higher, but not significantly so, among the $35-$ year-olds compared with the 15-year-olds, for income and smoking (2.04 and 1.37 for richer compared with poorer families, and 1.83 and 1.32 for non-smokers compared with smokers for 35-year-olds and 15-year-olds respectively). 


\section{DISCUSSION}

\section{Body weight}

The anthropometric values in these Scottish children for height, weight and BMI were similar to those reported by the Department of Health (1989), suggesting that they were no less well nourished than children of the same age in other parts of the UK. The larger standard deviations in males reflect the variation in age of the pubertal growth spurt. Despite the normal range of BMI, many of this sample felt they were 'too heavy', suggesting an awareness of body shape or image and a dissatisfaction with their own (this was particularly marked among the females). It will be interesting to observe from future data collection whether this concern with body image will alter with age.

\section{Food frequency}

The food-frequency data provides interesting information on patterns of food intake amongst Scottish adolescents. Although the contributions of specific foods to nutrient content cannot be assessed, foods which are consumed frequently can be identified and documented. This is especially important for designing dietary advice programmes, which need primarily to address foods and meal patterns rather than nutrients.

The daily consumption of crisps, sweets and biscuits illustrates the popularity of these manufactured products in the diet. Chip consumption is also notable, with almost half the sample consuming chips most days. It is unclear whether chips are provided at home or by catering establishments. (Gardner Merchant Ltd (1990) reported that $85 \%$ of schools in Scotland serve chips five times weekly compared with just over half of schools in London/Southern region). Commenting on the diets of British schoolchildren, Wenlock (1990) recommended a reduction in the quantity of chips and associated fatty foods in order to promote the reduction in dietary fat from the current $38 \%$ of energy to the Committee on Medical Aspects of Food Policy recommendation of 35\% of energy (Department of Health and Social Security, 1984). Apart from the issue of chips as a snack food, there are two other potential problems associated with their consumption. The first is that the most popular dishes eaten in this age-group in the West of Scotland were described by Cresswell et al. (1983) as 'fish and chips', 'cold meat and chips' and 'chips, bacon, egg and sausage'. Thus, chips tend to be accompanied by other high-fat foods which may increase total fat consumption even further. Second, Cresswell et al. (1983) reported that these dishes are never served with vegetables. This type of meal is likely, therefore, to lead to a low intake of dietary fibre and antioxidant vitamins (e.g. $\beta$-carotene, vitamin $\mathrm{C}$ ).

The daily consumption of cereals is rather encouraging because they are a reasonable source of dietary fibre with some varieties providing significant quantities. However, most of the food items rarely consumed by this sample are those which are widely promoted for general health (poultry, fish, pasta/rice, salads in winter, root vegetables, cooked green vegetables and fruit juice). The data presented here provide an interesting contrast to the dietary intake of French schoolchidren in their late teens (15-19 years old) reported by Michaud et al. (1991). They reported that $86 \%$ of children consumed green vegetables, $74 \%$ fresh fruit and $45 \%$ fruit juice daily. There is little evidence from the present data that Scottish adolescents are currently consuming such a healthy selection of foodstuffs. Undoubtedly the poorer climate and higher production/marketing costs of fruit and vegetables in Scotland may contribute to these eating patterns, although other social and cultural issues are likely to be important influences.

Low intakes of vegetables probably arise from a reliance on snack meals as opposed to 'proper meals' which are characterized by the presence of cooked vegetables (British 
Nutrition Foundation, 1985; we have reported elsewhere on the snacking patterns among this sample (Anderson et al. 1993)). Thus snack meals and manufactured snacks (cakes, biscuits and crisps) probably account for low intakes of antioxidant vitamins (A, C, E) which are associated with cardioavascular disease (Duthie et al. 1989). There is, however, no unequivocal evidence of the direct effects of snacking on health.

The relatively low frequency of consumption of yoghurts and puddings, which are generally eaten at meal times, again suggests that a significant proportion of energy is derived from non-traditional meal/snack items.

\section{Food habits and preferences}

At this age the types of spread, milk and bread consumed may be less a matter of individual choice than of what is provided in the home and at school. Thus, the high proportion of 15 -years-olds eating fats other than butter is unlikely entirely to reflect personal choice. By contrast, more of this sample said they would prefer brown or wholemeal bread than were actually eating it. A much more detailed study than the one reported here would be needed to ascertain the extent to which the food and drinks reportedly consumed by this group depended on their own choice, or on the choices made by others such as parents or schools. Factors such as the availability and price of foods locally, the dietary habits of other family members, or the time and equipment available for food shopping, storage, preparation and cooking, are also likely to play an important role in food selection.

\section{'Healthy eating' index}

The 'healthy eating' index used in the present study is meant only as a marker of healthrelated dietary behaviours which have been promoted by local health promotion programmes, and is limited in its use as an indicator of nutrient intake. The higher proportion of 'healthy eaters' amongst more socially advantaged young persons is not an unexpected finding and is in agreement with the findings of the Health and Lifestyle Survey (Cox et al. 1987; Blaxter, 1991), the Department of Health survey of the diets of schoolchildren (Department of Health, 1989), and the 35-year-old cohort of the West of Scotland Twenty-07 study (Anderson \& Hunt, 1992). Results from the multivariate analysis indicate that the social class of parents is an important predictor of 'healthy eating', even after adjusting for parental income. This suggests that aspects of social class position such as education, values, availability of time, and area of residence may influence dietary provision. The tendency for females to eat more 'healthily' than males even after adjustment for social class and income emphasizes that sex is an important predictor of diet, either because of the sort of diets females typically choose or because of the diets they are typically given. Concern about weight and appearance in teenage girls is also likely to affect their intake of fatty foods and fruit (the latter often being seen as 'slimming').

The relationship between smoking and poor dietary intake in adults has been well documented (Fehilly et al. 1984; Whichelow et al. 1988; Morabiat \& Wynder, 1990; Herbert \& Rabout, 1990; Cade \& Margetts, 1991). In general, smoking has been associated with decreased intake of fruit and vitamin $\mathrm{C}$ and higher intakes of fat and alcohol. Although the number of smokers in the present study was quite small, the combination of smoking and a 'less healthy diet' has obvious implications for long-term health.

\section{Comparison with 35-year-olds}

The proportion of 15-year-olds classified as having 'healthy diets' was less than the proportion of 35-year-olds so classified, which confirms the trend illustrated by the differences in individual food consumption patterns. It is also consistent with findings from the Oxford Region Healthy Life Survey to the effect that 18-24 year olds were the 
most likely, and 3544 year olds the least likely, to report 'unhealthy' diets (Thorogood \& Coulter, 1992). We have no reason to suppose that the diets of the parents of these 15-yearolds are substantially different from those reported by the 35 -year-olds. This would suggest that the influence of parents on their adolescent children's eating patterns is limited. It is also of interest that there was less differentiation in 'healthy eating' by social characteristics such as social class, income or sex among the younger cohort compared with the older one. This relative uniformity in eating patterns may reflect the influence of the 'youth industry' in fostering and sustaining particular patterns of choice and preferences for 'fast foods', 'fast drinks', and 'designer labels' in general. It may also reflect a relatively uniform rejection of parental values.

It is unclear whether the number of young persons eating 'healthily' is a reflection of personal food choices; of the preferences of (or constraints imposed on) their parents and other suppliers of food (e.g. school canteens); or peer pressure to conform to 'acceptable' eating habits. Details of the dietary intake of young people who move from their parental home over the next few years will be available from later sweeps of data collection of the Twenty-07 Study undertaken in 1990 and subsequently (West \& Sweeting, 1992), and may help to enhance our understanding of the influence of early food provision, as compared with other influences, in establishing the eating habits of adulthood.

\section{Dietary knowledge}

Knowledge about foods considered to be beneficial for healthy weight reduction or maintenance was good for high-fat or sugar items (e.g. chips and sweets) and for fresh fruit and vegetables, but less good for potatoes, bread and red meat, which may reflect the confusion that has arisen following changes in nutritional guidance on such foods. A recent survey on schoolchildren's understanding of healthy foods, conducted by a catering company (Gardner Merchant Ltd, 1990), showed similar results for knowledge about jacket potatoes in this age-group (15-16 years), although fewer younger children (13-14 and 11-12 years) perceived them as healthy.

Although knowledge about foods appropriate for weight control seems reasonable, there is little evidence from the present study that adolescents are familiar with food patterns associated with long-term health. That only half recalled learning about diet at school is a striking statistic given that all boys and girls in Scottish schools should have received some lessons in home economics.

The food-frequency data suggest a real failure of nutrition education to influence eating habits in this age-group. This issue has been discussed by Lean \& McFarlane (1991), who suggest that nutrition education has failed because of a tendency to divorce nutrition education from the context of eating behaviour and to separate it from the more general field of health education. Current health promotion programmes tend to focus on the role of dietary advice for prevention of diseases such as coronary heart disease and cancer which may not be perceived as relevant to adolescents. However, among adolescents the occurrence of Fe-deficiency anaemia (especially given its link with learning abilities (Pollitt et al. 1985)), dental decay (Todd \& Dodd, 1985), and obesity (Poskitt, 1991) may be perceived as of more immediate relevance by teenagers and so should be addressed in nutrition education programmes. Lean \& McFarlane (1991) also argue that before nutrition education can be effective in schools, teachers must aim not only to improve knowledge but also to help pupils to develop skills in making choices, taking decisions and managing peer pressure. The current findings suggest that parents and food providers outside the school environment also need to be involved in nutrition education programmes.

The diets of young women before or during their childbearing years have recently been re-emphasized as potentially extremely important for the health of the next generation 
(Barker et al. 1989). Current fertility rates of 40 per 1000 among 15-19 year olds in Scotland (Royal College of Obstetricians and Gynaecologists, 1991) suggest that the diet of adolescent women should be of concern not only with regard to their own health, but also with regard to the health of their offspring.

\section{Conclusions}

The meal patterns and food frequencies reported amongst 15-year-olds in the West of Scotland in the late-1980s are not consistent with local current dietary advice. Being female, coming from non-manual background and higher income families, and not smoking are important predictors of 'healthy' diets at this age, as they are at older ages.

This work was supported by the Medical Research Council of Great Britain. The authors wish to thank Russell Ecob, Kate Hunt, Mike Lean, Jean Leiper and Helen Sweeting for assistance with this paper.

\section{REFERENCES}

Anderson, A. S., Foster, A., Lean, M. E. J. \& Marshall, D. (1994). Ripe for change: Fruit and Vegetables in Scotland. Health Bulletin (In the Press).

Anderson, A. \& Hunt, K. (1992). Who are the healthy eaters? Eating patterns and health promotion in the West of Scotland. Health Education Journal 51, 3-10.

Anderson, A., Macintyre, S. \& West, P. (1993). Adolescent meal patterns: grazing habits in the West of Scotland. Health Bulletin 51(3), 158-165.

Barker, D. J. P., Osmond, C. \& Law, C. (1989). The intra-uterine and early post-natal origins of cardiovascular disease and chronic bronchitis. Journal of Epidemiology and Community Health 43, 237-240.

Black, R. (1985) Instead of the 1985 Census; the potential contribution of enhanced registers. Journal of the Royal Statistical Socioty 148, 287-316.

Blaxter, M. (1991). Health and Lifestyles. London: Routledge.

British Nutrition Foundation (1985). Eating in the Early 1980's. London: British Nutrition Foundation.

Bull, N. L. (1985). Dietary habits of 15 to 25 year olds. Human Nutrition: Applied Nutrition 38 A, 1 suppl.

Cade, J. E. \& Margetts, B. M. (1991). Relationship between diet and smoking - Is the diet of smokers different? Journal of Epidemiology and Community Health 45, 270-272.

Cox, B., Blaxter, M., Buckle, A. L. J., Fenner, N. P., Goiding, J. F., Gore, M., Huppert, F. A., Nickson, J., Roth, M., Stark, J., Wadsworth, M. E. J. \& Whichelow, M. (1987). The Health and Lifestyle Survey; Preliminary Report. Cambridge: Health Promotion Research Trust.

Cresswell, J., Busby, A., Young, H. \& Inglis, V. (1983). Dietary patterns of third-year secondary schoolgirls in Glasgow. Human Nutrition: Applied Nutrition 37A, 301-306.

Department of Health (1989). The Diets of British Schoolchildren. Report of Health and Social Subjects no. 36. London: H.M. Stationery Office.

Department of Health and Social Security (1984). (Diet and Cardiovascular Disease. Report of the Committee on Medical Aspects of Food Policy. London: H.M. Stationery Office.

Duthie. G. G.. Wahle, K. W. J. \& James, W. P. T. (1989). Oxidants, antioxidants and cardiovascular disease. Nutrition Research Reviews 2, 51-62.

Ecob, R. (1987). West of Scotland Twenty-07 Study: The Sampling Frame and Procedures for the Cohort Studics. MRC Medical Sociology Unit Working Paper no. 6. Glasgow: MRC Medical Sociology Unit.

Fehilly, A. M., Philips, K. M. \& Yarnell, J. W. G. (1984). Diet, smoking, social class and body mass index in the Caerphilly Heart Disease Study. American Journal of Clinical Nutrition 40, 827-833.

Gardner Merchant Ltd (1990). School Meals Survey. Swindon: Gardner Merchant Ltd.

Greater Glasgow Health Board (1987). Are You a Hearty Eater? Glasgow: GGHB.

Hackett, A. F., Rugg-Gunn, A. J., Appleton, D. R. \& Coombs, A. (1986). Dietary sources of energy, protein fat and fibre in 375 English adolescents. Human Nutrition: Applied Nutrition 40A, 176-184.

Herbert, J. R. \& Rabout, G. C. (1990). Differences in dietary intake associated with smoking status. American Journal of Clinical Nutrition 44, 135-193.

Lean, M. E. J. \& McFarlane, M. (1991). Nutrition education in Scottish schools, Proceedings of the Nutrition Society 50, $45-48$.

Macintyre, S., Annandale, E. \& Ecob, R. (1989). The West of Scotland Twenty-07 Study: Health in the Community. In Readings for a New Public Heath. [C. Martin and D. J. MacQueen, editors]. Edinburgh: Edinburgh University Press.

Maciver, S. (1988). West of Scotland Twenty-07 Study; Sociodemographic and mortality profles of the study areas. MRC Medical Sociology Unit Working Paper no. 10. Glasgow: MRC Medical Sociology Unit. 
MacNeill, G., Davidson, L., Morrison, D. C., Crombie, I. K., Keighran, J. \& Todman, J. (1991). Nutrient intake in schoolchildren: some practical considerations. Proceedings of the Nutrition Society 50, 37-43.

Michaud, C. (1991). Sources of macronutrients and energy in the diet of a group of French high-school students on school-days. Journal of Human Nutrition Dietetics 4, 91-100.

Morabiat, A. \& Wynder, E. L. (1990). Dietary habits of smokers, people who never smoked and ex-smokers. American Journal of Clinical Nutrition 57, 933-937.

Nelson, M., Naismith, D. J., Burley, V., Gatenby, S. \& Geddes, N. (1990). Nutrient intakes, vitamin-mineral supplementation, and intelligence in British schoolchildren. British Journal of Nutrition 64, 13-22.

Nie, N., Hill C. \& Jenkins, J. (1983). SPSSX. Statistical Package for the Social Sciences. New York: McGraw Hill.

Office of Population Census and Surveys (1981). Registrar Generals Classification of Occupation 1980. London: H.M. Stationery Office.

Pollitt, E., Soemantri, A. G., Yunis, F. \& Scrimshaw, N. S. (1985). Cognitive effects of iron-deficiency anaemia. Lancet ii, 158.

Poskitt, E. M. E. (1991). Early diet later obesity? British Nutrition Foundation Bulletin 16, suppl., 38-44.

Royal College of Obstetricians and Gynaecologists (1991). Report of the RCOG Working Party on Unplanned Pregnancy. London: RCOG.

Smith, W. C. S., Tunstall-Pedoe, H., Crombie, I. K. \& Tavendale, R. (1989). Concomitants of excess coronary deaths: major risk factors and lifestyle findings from 10,359 men and women in the Scottish Heart Health Study. Scottish Medical Journal 34, 550-555.

Thomas, J. (1990). Food choices and preferences of schoolchildren. Proceedings of the Nutrition Society $\mathbf{5 0}$, 49-57.

Thorogood, M. \& Coulter, A. (1992). Food for thought; women and nutrition. In Women's Health Matters. [H. Roberts, editor]. London: Routledge.

Todd, J. E. \& Dodd, T. (1985). Children's Dental Health in the UK 1983: A Survey Carried Out by the Social Survey Division of $O P C S$. London: H.M. Stationery Office.

Truswell, S. \& Darton-Hill, J. (1981). Food habits of adolescents. Nutrition Reviews 39, 73-88.

Tunstall-Pedoe, H., Smith, W. C. S., Crombie, I. K. \& Tavendale, R. (1989). Coronary risk factor and lifestyle variation across Scotland; results from the Scottish Heart Health Study. Scottish Medical Journal 34, 556-560.

Wenlock, R. W. (1990). The diets of British Schoolchildren. Journal of the Royal Society of Health 2, 50-53.

West, P. \& Sweeting, H. (1992). Distribution of basic information from the 1990 follow-up of the Twenty-07 Study youth cohort. MRC Medical Sociology Unit Working Paper no. 32, Glasgow: MRC Medical Sociology Unit.

Whichelow, M., Golding, J. F. \& Treasure, F. F. (1988). Comparison of some dietary habits of smokers and nonsmokers. British Journal of Addiction 83, 295-304.

World Health Organization (1990). Diet, Nutrition And The Prevention Of Chronic Diseases. Technical Report Series no. 797. Geneva: WHO. 